\title{
O GÓTICO E A VAMPIRIZAÇ̃̃o DA HISTÓRIA
}

\section{GOTHIC AND THE VAMPIRIZATION OF HISTORY}

\author{
Fernando Monteiro de Barros ${ }^{1}$ \\ O alto gótico é abstrato e cerimonioso. O mal tornou-se glamour, blasé, \\ hierárquico. Não há bestialidade. O tema é o poder ocidental erotizado, o \\ fardo da história.
}

Camille Paglia, Personas sexuais.

\begin{abstract}
RESUMO: $O$ ano de 1764 assinala o surgimento do romance gótico com a publicação de $O$ castelo de Otranto, de Horace Walpole. Confrontando os valores do Iluminismo da época, o romance de Walpole estabelece os pressupostos do que se constituirá como um dos mais duradouros gêneros da ficção ocidental. A presença da História é essencial tanto para o gênero quanto para o modo gótico, trazendo o elemento do passado que assombra o presente na modernidade, a partir de cenários que remetem à Idade Média ou pelo menos ao Ancien Régime. Entretanto, a História é representada de forma teatralizada, no que ela sinaliza a condição dramática moderna de um mundo desprovido de sentido onde o que permanecem são simulacros e fantasmagorias. Nesse sentido, o Gótico se utiliza da História de forma desautorizada, vampirizando-a.
\end{abstract}

PALAVRAS-CHAVE: Gótico; História; simulacro; fantasmagoria

\begin{abstract}
The year of 1764 marks the appearance of the Gothic novel with the publication of Horace Walpole's The castle of Otranto. Confronting the ongoing Enlightenment values, Walpole's novel sets the tone for what is to become one of the longest genres in Western fiction. History is essential to both the Gothic genre and the Gothic mode; it is a mark of the past that haunts present modernity, embodied by settings that are linked to the Middle Ages or at least to the Ancien Régime. However, in Gothic fiction History is portrayed in a stagey manner, as it conveys the dramatic modern condition of a world without meaning where all that remains are simulacra and phantasmagoria. In that respect, Gothic makes use of History in an unauthorized manner, as do vampires with their prey.
\end{abstract}

KEYWORDS: Gothic; History; simulacra; phantasmagoria

\footnotetext{
${ }^{1}$ Doutor em Letras pela UFRJ. Professor do Departamento de Letras da Faculdade de Formação de Professores da UERJ - campus São Gonçalo e docente do PPG em Letras e Linguística.
} 
O Gótico literário do século XVIII talvez seja um dos gêneros mais associados ao espaço. Castelos, mosteiros, abadias, criptas determinavam a cenografia dos romances de Horace Walpole (The castle of Otranto, 1764), Ann Radcliffe (The mysteries of Udolpho, 1794; The Italian, 1797) e Matthew Lewis (The monk, 1796), com construções portentosas do mundo medieval e marcadas pela ruína que, dessa forma, estabeleciam uma relação intrínseca do gênero com a História, com todo o seu peso de passado e de tradição em um momento de euforia do Ocidente com a razão, a ciência e o progresso. Nas palavras de Fred Botting, "o Iluminismo, que produziu as máximas e os modelos da cultura moderna, também inventou o Gótico" (BOTTING, 2012, p. 13). Essa “invenção do Gótico" implicou em uma constante e permanente "reescrita da História" (BOTTING, 2012, p. 13). O Gótico surgiu e tem permanecido uma estética, um gênero, um modo, “assombrado pelo peso da História” (PUNTER, 2012, p. 3).

No entanto, tal comparecimento da História se apresenta no Gótico com as marcas da teatralização - História e ficção se confundem, no constructo fantasioso que o Gótico faz do passado e da tradição que são alegorizados em signos marcados pelo sublime burkeano, com seu duplo eixo de terror e de esplendor. "História fabricada" (BOTTING, 2012, p. 14), a ficção gótica, por meio dos objetos esvaziados de sentido - pois são ostensivamente marcados pelo selo da falsificação (HOGLE, 1994, p. 23) - parece representar a fantasmagoria da modernidade, na qual os sentidos são cada vez mais fugidios e plurais. É famosa a cena de Otranto na qual um dos retratos na galeria do castelo suspira e sai da tela. Uma das características do Gótico é a sua extrema teatralidade, pois o cenário e o décor assumem a dimensão talvez mais importante para a constituição do gênero. Ostentando acintosamente sua característica de "fenômeno estético fabricado e artificial" (BOTTING, 2012, p. 14), Otranto, o romance marco dessa lavra, em sua primeira edição, já prima, sob vários aspectos, por esta marca da falsificação, que, de acordo com o crítico Jerrold E. Hogle (1994), está expressa não apenas na apropriação estilizada que o Gótico faz da História, mas também no recurso, enganoso para os leitores da primeira edição, do manuscrito encontrado e traduzido. Assim, desde o início o Gótico prima por seu caráter de simulacro, o que pode ter contribuído para que não fosse levado a sério por um longo tempo. "A artificialidade que cerca as origens históricas e culturais das produções góticas permaneceu um fator tanto de crítica quanto de emulação durante o século XVIII", ressalta Fred Botting (2012, p. 15). Nas palavras de Jerrold E. Hogle, o Gótico opera uma "manipulação cênica" dos objetos e cenários da História, "divorciando tais artefatos de suas fundações e convertendo-os em bric-a-brac, signos descolados de sua 
substância original" (HOGLE, 1994, p. 23). Para Hogle, tal abordagem dos "fragmentos do passado", ao mesmo tempo "bem pesquisados" historicamente, porém recuperados de forma "esvaziada e inautêntica", por ao mesmo tempo imitar a História medieval e dela se distanciar, teria originado "um modo - nos romances, nas artes, nos filmes" marcado pela falsificação e pelo esvaziamento do signo, que seria, até os dias de hoje, bastante "popular na produção ficcional do Ocidente" (HOGLE, 1994, p. 23). De fato, Hogle sugere que o Gótico walpoleano teria contribuído para a visão ocidental "dos signos e dos artefatos como sendo essencialmente falsificados" (HOGLE, 1994, p. 25). Hogle cita Jean Baudrillard para fundamentar que tais origens do Gótico do século XVIII teriam estreita relação com o que Baudrillard propõe a respeito do modo como no Ocidente os signos têm se relacionado com os referentes nos últimos quatro séculos, começando na Renascença: para Baudrillard “a falsificação" é o "esquema dominante" da representação desde o Renascimento até o surgimento da Revolução Industrial (HOGLE, 1994, p. 29-30).

Com efeito, em Simulacros e simulação Jean Baudrillard, ao falar sobre o cinema no século XX e sobre a fantasmagoria dos objetos cênicos, parece falar também sobre o contexto gótico:

\footnotetext{
No "real" como no cinema, houve história mas já não há. A história que nos é "entregue" hoje em dia (justamente porque nos foi tomada) não tem mais relação com um "real histórico" que a neofiguração em pintura com a figuração clássica do real. A neofiguração é uma invocação da semelhança, mas ao mesmo tempo a prova flagrante do desaparecimento dos objetos na sua própria representação: hiper-real. Os objetos têm aí, de alguma maneira, o brilho de uma hipersemelhança (como a história no cinema atual) que faz com que no fundo não se assemelhem a nada senão à figura vazia da semelhança, à forma vazia da representação. É uma questão de vida ou de morte: esses objetos já não são vivos nem mortais. É por isso que são tão exatos, tão minuciosos, tão condensados, no estado em que os teria captado uma perda brutal do real. (BAUDRILLARD, 1991, p. 62)
}

Com efeito, a modernidade engendrou o divórcio entre o nome e a coisa. Anatol Rosenfeld informa que na Idade Média preponderava "o realismo conceitual ou das universálias: a nomes e conceitos" corresponderiam "essências ou formas" (ROSENFELD, (1976, p. 123), uma vez que "as ideias gerais têm um ser intemporal no logos divino, mesmo antes de haverem sido criadas as coisas temporais e individuais" (ROSENFELD,1976, p.124). Tal realismo conceitual estava ligado à visão teocêntrica do mundo medieval. De Deus ao ser humano a perfeição ia diminuindo (ROSENFELD, 1976, p.124), e tal pensamento, hierárquico e teocêntrico, deixava o mundo pleno de sentido. Já na virada da Idade Moderna, com o ocaso desse teocentrismo, se deu o advento do nominalismo, segundo o qual "somente às coisas 
individuais, temporais, deve ser atribuída plena realidade” (ROSENFELD, 1976, p.126) e, consequentemente, "os conceitos gerais que delas formamos pelo processo de abstração são apenas nomes" (ROSENFELD, 1976, p.126). Rosenfeld salienta que dentro da antiga visão teocêntrica o ser humano era "parte do plano divino universal" (ROSENFELD, 1976, p. 130), ao passo que, a partir da modernidade, com o Renascimento, no antropocentrismo, "a transcendência cede terreno à imanência, o outro mundo a este, o céu à terra, o intemporal ao temporal" (ROSENFELD, 1976, p. 129) e, desse modo, o ser humano passou a perceber que habitava um universo "que não [era] mais explicado, transparente e ordenado" (ROSENFELD, 1976, p. 131).

A Divina Comédia representa essa ordem universal teocêntrica da Idade Média. Segundo Octávio Paz, a obra-prima de Dante Alighieri - que viveu da segunda metade do século XIII às primeiras décadas do século XIV - apresentava em sua concepção um mundo fechado, estruturado, onde cada coisa tinha o seu lugar na ordem do universo. Já Hamlet de William Shakespeare, escrito entre 1599 e 1601, considerado o primeiro drama moderno, seria a primeira obra literária ocidental a apresentar a perda de centro e de sentido do mundo novo da modernidade. "Com efeito, o homem moderno começa a falar pela boca de Hamlet", diz Octavio Paz (1990, p. 19), que acrescenta:

\footnotetext{
Desaparecido o mundo de valores cristãos - cujo centro é, justamente, a universal analogia entre céu, terra e inferno - nada resta ao homem, exceto a associação fortuita e casual de pensamentos e imagens. O mundo moderno perdeu o sentido e o testemunho mais cru desta ausência de direção é o automatismo da associação de ideias, que não está regido por nenhum ritmo cósmico ou espiritual, mas pelo acaso. Todo esse caos de fragmentos e ruínas apresenta-se como a antítese de um universo teológico, ordenado conforme os valores da Igreja romana. (PAZ, 1990, p. 20)
}

Em sua obra Origem do drama barroco alemão, Walter Benjamin aponta que tal ausência de sentido do mundo moderno, sintetizada acima por Octavio Paz, teria se dado mais intensamente nos países protestantes. Ao falar sobre o Barroco, Benjamin diferencia a manifestação que este estilo artístico-literário teve na Espanha católica (já que, de algum modo, a Contra-Reforma indiretamente procurou recuperar o sentido do mundo, na sua reedição do teocentrismo medieval) da manifestação que este teve na Alemanha protestante, na qual o Barroco não mais contava com o lastro do divino e apresentava o ser humano entregue à sua própria sorte em um mundo que, regido unicamente pelas leis da imanência, se apresentava como um labirinto: 
Enquanto a Idade Média mostra a fragilidade da história e a perecibilidade da criatura como etapas no caminho da redenção, o drama alemão mergulha inteiramente na desesperança da condição terrena. Se existe redenção, ela está mais no abismo desse destino fatal que na realização de um plano divino, de caráter soteriológico. A rejeição do elemento escatológico inerente ao teatro religioso caracteriza o novo drama em toda a Europa. Mas a fuga cega para uma natureza desprovida de Graça é especificamente alemã. Pois o drama da Espanha, o mais perfeito da Europa, e que desenvolve, nessa cultura católica, traços barrocos muito mais brilhantes, mais característicos e mais bem-sucedidos, consegue resolver os conflitos resultantes de um estado de Criação destituído de graça, cuja representação em miniatura é a corte de um monarca que detém, em sua forma secularizada, o poder de redimir. (BENJAMIN, 1984, p. 104)

Efetivamente, segundo Benjamin, no Luteranismo passou a preponderar a "crença sombria na sujeição do homem ao destino", pois nele "as ações humanas foram privadas de todo valor", e, consequentemente, "algo novo surgiu: um mundo vazio" (BENJAMIN, 1984, p. 162). E, sobre este "mundo vazio", fazem-se oportunas uma vez mais as palavras de Jean Baudrillard, que, ao discorrer sobre o cinema no século XX, fala deste contexto da experiência de perda de sentido na modernidade, que vem desde o Renascimento:

É neste vazio que refluem os fantasmas de uma história passada, a panóplia dos acontecimentos, das ideologias, das modas retrô - não tanto por que as pessoas acreditem ou depositem aí qualquer esperança, mas simplesmente para ressuscitar o tempo em que pelo menos havia história... tudo serve para escapar a este vazio... (BAUDRLLARD, 1991, p.60)

É de se perguntar por quê a ficção gótica teria surgido e florescido nos países do norte da Europa, anglo-germânicos, e demorado a fincar seus pés nos países latinos do sul europeu, mesmo embora, curiosamente, tais países meridionais banhados pelo Mediterrâneo constituíssem o locus onde tais narrativas assombrosas se desenrolavam. Por quê o Gótico vicejou nos países protestantes já no século XVIII e só chegou muito tempo depois aos países católicos? Talvez a resposta para tal questionamento tenha a ver com o fato de que, em pleno século XVIII iluminista, o mundo ibérico - bem como a Península Itálica - estava dominado pelo catolicismo e pela Inquisição, que só foi abolida em Espanha e Portugal no século XIX, e portanto era, na época de Walpole, ainda dotado de uma visão que pretendia dar conta da explicação do mundo por um viés transcendental que, mesmo de forma impositiva (como também o havia sido no contexto medieval), proferia um discurso que atribuía algum sentido ao universo.

Tal viés protestante nos parece extremamente importante para pensarmos em um fio condutor que ligaria o romance gótico inglês setecentista ao drama barroco alemão. A falta de transcendência da visão de mundo luterana, puramente imanentista, conforme diz Walter 
Benjamin, parece estar na base do elo muitas vezes já apontado por diversos críticos entre Hamlet (identificado por Benjamin com o drama barroco alemão) e Otranto.

O romance de Walpole apresenta um príncipe que traz as marcas do tirano barroco, e não é gratuito que o autor, no prefácio à sua segunda edição, tenha prestado tributo a Shakespeare e afirmado tê-lo tomado por modelo. No drama barroco, tal como em Hamlet, "o tirano tem todo o poder e todo o medo, a história é palco de disputas e intrigas, não há momento nem lugar certo onde ocorrerá uma traição, nele impera o Soberano, suas ambivalências e ambiguidades", e nele "o Príncipe é, simultaneamente, a encarnação da história e criatura mortal" (MATOS, 2010, p.38). Em uma escrita menos suntuosa que a de Shakespeare, em um século XVIII que já assiste aos estertores do Ancièn Regime, da era aristocrática de que fala Harold Bloom (1995, p. 51), a simplicidade da escrita de Walpole parece sintomatizar a queda do refinamento com o fim das monarquias absolutistas e com a emergência da hegemonia burguesa; José Guilherme Merquior atribui o que ele considera mau-gosto kitsch da escrita de Walpole à ampliação do púbico leitor e à queda dos padrões estéticos da aristocracia com a ascensão da burguesia: "nem foi por acaso que o movimento [o Gótico literário] foi mais forte na Inglaterra, então a mais aburguesada das nações europeias” (MERQUIOR, 1979, p. 56).

Esta relação entre Hamlet e $O$ castelo de Otranto se faz presente não apenas no prefácio da segunda edição e na correspondência entre o tirano barroco e o vilão gótico, o qual, via de regra, costuma também ser principesco ou aristocrático. As considerações de Jerrold E. Hogle e Fred Botting anteriormente citadas sobre a teatralidade e o caráter de falsificação da ficção gótica também nos permitem nela perceber ressonâncias profundas do Barroco alemão. Assim como no drama barroco, no qual os objetos e o cenário funcionam como alegorização da História, o espaço gótico também traz essa marca do simulacro. Estética do falsificado, conforme a visão de Hogle, o Gótico literário depende como nenhum outro gênero do cenário e dos objetos que o compõem.

Benjamin, em sua já citada obra, apresenta o seu conceito de alegoria pelo qual a representação não tem mais uma correspondência exata de sentido prontamente reconhecível e identificável. O filósofo nos mostra que, no drama barroco do século XVII, a História se converte em teatro. Neste teatro, os objetos adquirem uma carga simbólica representacional máxima. O cetro, a coroa, o manto, o trono são mostrados como alegorias da História. $\mathrm{O}$ príncipe barroco, acometido de loucura e tomado pela crueldade, sinaliza a experiência humana do desamparo máximo da criatura em um mundo que já perdeu o sentido. A esse respeito, Lauro 
Junkes sintetiza o conceito benjaminiano de alegoria barroca, que, como podemos ver, possui estreita relação com o esvaziamento do signo a partir do surgimento da Idade Moderna:

\begin{abstract}
As ideias não se situam, para Benjamin, num mundo a parte, conforme propõe o sistema de Platão. Elas têm por recinto próprio a dimensão nomeadora da linguagem, que contrasta com sua dimensão significativa e comunicativa: "A ideia é algo de linguístico, e o elemento simbólico presente na essência da palavra". A linguagem adâmica do Paraíso despertava as coisas, chamando-as pelo nome, identificando nome e coisa. Para Deus e, no início, para os homens, criar e conhecer como que se confundiam, completando o homem a criação de Deus. Com a expulsão do Paraíso, após a queda, a linguagem tornou-se profana, degradou-se num processo que terminou em mero sistema de signos, conforme será em seguida melhor explanado. Se Benjamin, na sua teoria da arte, opõe "alegoria" a "símbolo", opõe também, na sua teoria da linguagem, "nome" a "signo". Enquanto o "nome", na sua transparência divino-paradisíaca, indica a linguagem como "manifestação", o "signo" constitui decorrência da degradação após a queda e expulsão, marcando a linguagem como "instrumento" de comunicação. (JUNKES, 1994, p. 125)
\end{abstract}

A modernidade, em sua rasura da explicação teocêntrica do universo, parece configurar essa "queda do Paraíso" - a que Benjamin posteriormente irá relacionar também à época de Baudelaire, o século XIX com o advento do capitalismo da era industrial e do império das mercadorias, objetos-fetiche (AGAMBEN, 2007, p. 68).

Voltando à relação entre o Barroco protestante e o romance gótico, é digna de nota a citação que Benjamin faz de Konrad Burdach, em que este diz que a contrapartida do Homem da Renascença é "o Homem Gótico, que desempenha hoje um papel perturbador e que prega suas peças fantasmagóricas até mesmo no universo intelectual de historiadores respeitáveis" (BENJAMIN, 1984, p. 63), o que parece sinalizar o caráter saturnino e crepuscular da modernidade, tão bem alegorizado pelo Gótico.

Tanto no Barroco como no Gótico a História comparece, portanto, como cenário teatral. Alegorias da tradição se manifestam através dos elementos cenográficos. A galeria dos quadros dos antepassados sublinha tal fantasmagoria evocada por cenário e objetos. A "diferença entre a representação simbólica e a alegórica" - na qual o símbolo possui uma relação intrínseca de sentido com o referente e a alegoria não - é, que "no caso do símbolo, o conceito baixa no mundo físico, e pode ser visto na imagem, em si mesmo, e de forma imediata", enquanto que a alegoria "significa apenas um conceito geral ou uma ideia, que dela permanece distinta; a primeira [o símbolo] é a ideia em sua forma sensível, corpórea", ao passo que "no caso da alegoria, há um processo de substituição", diz Benjamin citando Friedrich Creuzer (BENJAMIN, 1984, p. 186-187). 
Na modernidade, mundo esvaziado de sentido, reinam as alegorias. Para Benjamin, “o deus do teatro novo é o artifício" (1984, p. 105). No palco, "o soberano representa a história. Ele segura em suas mãos o acontecimento histórico, como se fosse um cetro" (BENJAMIN, 1984, p. 88). E, no drama barroco, "a história migra para a cena teatral” (BENJAMIN, 1984, p. 115). De fato, "a concepção da história do século XVII foi definida como panoramática", pois "nesse mesmo período pitoresco, a concepção da história é determinada pela justaposição de todos os objetos memoráveis", efetivando "a secularização da história na cena do teatro", atesta Benjamin, citando Herbert Cysarz sobre o Barroco alemão (1984, p. 115). Em suas palavras, "a imagem do palco, ou mais exatamente, da corte, se transforma na chave para a compreensão da história" (BENJAMIN, 1984, p. 115) e "o drama vê na corte o décor eterno e natural do processo histórico" (BENJAMIN, 1984, p. 115).

Deste modo, no espaço e nos objetos, Benjamin proclama esta visão moderna da História como fantasmagoria, preponderante no Barroco alemão - e que terá fortes reverberações na literatura gótica surgida no século XVIII. "Os Príncipes, nascidos para a púrpura, ficam enfermos quando estão sem cetro", cita Benjamin, que em seguida afirma: "esse verso de Lohenstein justifica a comparação entre o governante do teatro barroco e um rei de baralho" (BENJAMIN, 1984, p. 148), atestando o esvaziamento de sentido da experiência moderna. A fatalidade, portanto, não é distribuída apenas entre os personagens, ela está igualmente presente nas coisas: "a tragédia de destino não se caracteriza apenas pela transmissão hereditária a várias gerações de uma maldição ou de uma culpa, mas também pela vinculação a um objeto fatal, que faz parte do cenário", diz Benjamin ao citar Jacob Minor (BENJAMIN, 1984, p. 148).

Portanto, em um mundo esvaziado de sentido, reina a espectralidade: "não é possível abstrair o adereço cênico da forma evoluída do drama do destino. Mas existem nele, além disso, os sonhos, as aparições espectrais, os terrores do fim, e todos esses elementos pertencem obrigatoriamente à sua forma fundamental, a do drama barroco" (BENJAMIN, 1984, p. 157). Desse modo, assim como sucederá no Gótico literário do século XVIII, no drama barroco alemão "a noite desempenha um papel importante, como se verifica pelas aparições e pelos efeitos fantasmagóricos" (BENJAMIN, 1984, p. 157-158), já que "o tempo noturno do drama barroco" (BENJAMIN, 1984, p. 158) irá também se espraiar na narrativa de Otranto e nas subsequentes do gênero. Para Platão, a arte era cópia do que já era cópia: imagem esvaziada de sentido, puro simulacro. Em grego, a palavra para simulacro é phántasma. Os objetos presentes no Gótico - quadros dos antepassados, móveis antigos, cetros, coroas, tronos, espadas e 
punhais, eivados de fantasmagoria - se relacionam aos três principais elementos desse modo narrativo: a presença fantasmagórica do passado no presente, o locus horribilis e a personagem monstruosa (FRANÇA, 2017, p. 24-25).

A partir das considerações expressas até aqui, arriscamos dizer que o Gótico - tanto enquanto gênero quanto como modo - faz uso da História a seu bel prazer, como bem quer, sem pedir licença, em uma relação parasitária com a mesma. O Gótico não dialoga com a História, mas sim vampiriza-a. O Gótico, ao fazer uma pilhagem desautorizada da História por meio do pastiche ou da paródia, converte-a em franja fúnebre e condena-a ao estatuto do simulacro. A História é aprisionada pelo Gótico e, ao ser por ele vampirizada, se converte em fantasmagoria.

Neste sentido, considerando o Gótico como uma poética da modernidade que apresenta profundas afinidades com o Barroco alemão, pensamos que para que haja a presença do Gótico seria preciso haver a presença de signos da História, em sua condição de avatar do mundo recalcado pela modernidade iluminista. Cenários medievais, ou mesmo cenários e personagens ligados ao Ancien Régime que desapareceu com as revoluções Industrial e Francesa do final do século XVIII, trazem a marca da fantasmagoria gótica. No mundo reificado da modernidade burguesa, capitalista, industrial, que se estabelece desde o fim dos setecentos até a nossa era, o que for ligado às duas classes que haviam sido poderosas até o final do Antigo Regime - a aristocracia e o alto clero - traz a marca do esteticismo gótico em sua relação teatralizada da História enquanto tradição derrotada e suplantada.

Nos valemos da exposição da filósofa Olgária Matos (apud BARROS, 2014, p. 88), quando esta traz a afirmação de Karl Marx sobre a questão da tradição face à modernidade, ao dizer que "o Antigo Regime é o pecado oculto do Estado Moderno" e que "a luta contra a situação política presente da Alemanha é a luta contra o passado dos povos modernos, e as reminiscências deste passado sempre vêm importuná-los" (MARX apud MATOS, 1995, p. 39). Em seguida, ao citar Walter Benjamin sobre o mesmo tópico - "a modernidade carrega a antiguidade como um mau espírito (wie einen $A l b$ ) que teria vindo importuná-la em seu sono. $A l b$ ou Alp: mau demônio, fantasma que à noite vem se postar no peito de quem dorme e provoca pesadelos (Alptraum)" (MATOS, 1995, p. 72-73) - Matos reitera tal associação e a finaliza com mais uma citação de Karl Marx retirada do 18 Brumário: "a tradição de todas as gerações mortas pesa como um mau espírito (wie ein Alp) sobre o cérebro dos vivos" (MATOS, 1995, p. 113), permitindo que possamos vislumbrar uma relação entre a tradição e a História enquanto assombração. 
Destarte, em nossa opinião, pensamos que provavelmente não haveria a presença do Gótico em filmes sobre "a volta dos mortos-vivos" ou em filmes de zumbis, pois o Gótico parece precisar de cenários que tenham a marca da História. História ocidental, do mundo europeu e suas margens e fronteiras, bem como do mundo europeu transplantado para as Américas. Um "Gótico asiático" nos soa improvável, ao passo que o mesmo não se poderia dizer sobre o Gótico latino-americano, o Gótico sul-estadunidense e o Gótico brasileiro, pois tanto o Brasil, quanto a América Latina e o sul dos Estados Unidos apresentam um forte legado da contraparte do mundo medieval no Novo Mundo, a herança de uma colonização baseada em um etos senhorial e estamental. Pois tal História fantasmática gótica parece necessitar das galas e dos atavios das classes sociais outrora poderosas e que, na modernidade industrial, se encontram derrotadas e não mais hegemônicas: a aristocracia e o alto clero católico. Assim, em nossa opinião, o Gótico parece necessitar desse elemento de choque de um passado ligado à tradição que assombraria o mundo democrático moderno.

Dentro dessa mesma clave, o Gótico nos parece ser incompatível com temas, cenários e personagens prosaicos. Os loci horribiles, espaços do medo onde se desenrolam os enredos góticos, são notórios por trazerem a marca da História e do passado: castelos, abadias, mosteiros, criptas, cemitérios, ou seja, cenários marcados pela cultura, portanto. A natureza por si só, por mais assustadora que seja (uma floresta densa, montanhas ameaçadoras, mares revoltos e bravios), em nossa opinião não traria sozinha a marca do Gótico, pois, segundo as hipóteses aqui desenvolvidas, este necessitaria da presença da História.

No Gótico que se consolida a partir do século XIX, os castelos dão lugar a mansões e a grandes casarões, mas estes parecem sempre trazer a marca de um passado aristocrático ou, pelo menos, afidalgado, senhorial. O cemitério, com a imponência lúgubre de suas criptas e mausoléus, com sua estatuária fúnebre, também cumpre esse papel. O locus horribilis gótico, por excelência, é apresentado não só como assombroso, sinistro e assustador, mas também como cenário espetacular, grandioso e portentoso. Seja castelo, mansão, cemitério, casa-grande sul-estadunidense ou brasileira, sempre o locus horribilis gótico parece ser marcado pela junção do sombrio com o esplendoroso. Este sombrio esplendor dos loci horribiles góticos se traduz em espaços labirínticos e imponentes na sua espetacularidade, ligados ao sublime burkeano tanto pelo terror quanto pela majestade de sua monumentalidade, nos quais a História, teatralizada e fantasmática, comparece em cheio. Portanto, em espaços desolados, desérticos, ou até mesmo sertanejos, sem o legado de um passado aristocrático ou senhorial consubstanciado em alguma construção portentosa e arruinada, não julgamos possível haver a 
presença do Gótico. Pois no Gótico teria que haver uma fusão do sinistro com o imponente, do tenebroso com o grave, em um tom melancólico e com marcas de solenidade. Pensamos que o Gótico precisa estar ancorado no sublime. Acreditamos que o tom imitativo alto relacionado à tragédia por Aristóteles precisaria estar presente para gerar a grandeza trágica e a melancolia precípuos ao Gótico. O imitativo baixo aristotélico que podemos relacionar a espaços, temas e personagens da burguesia, da classe média, do proletariado, ou seja, a espaços, temas e personagens prosaicos, não teria a marca do Gótico, em nossa opinião. Pois, para que haja Gótico, nos parece ser preciso que haja um certo élan - proveniente da História, do choque da tradição com a modernidade, da solenidade, da aristocracia - e daí viria o pathos do Gótico. $\mathrm{O}$ enredo tradicional do Gótico, a ruína do patriarcalismo, é, sabidamente, de cunho senhorial e aristocrático.

Também no Gótico do século XIX, e até os nossos dias, temos tido a presença de um outro espaço, não ligado exatamente às edificações históricas como castelos, mansões, mosteiros ou criptas, mas igualmente marcado pela História. Trata-se da grande cidade moderna da era industrial, a Paris noturna de Baudelaire com a fantasmagoria de suas vitrines, mercadorias e cenários, plena de charme infernal. Também a Londres nublada e soturna dos romances de Charles Dickens, Bram Stoker e Oscar Wilde. Ou o Rio de Janeiro sinistro, ameaçador e labiríntico de João do Rio. Aqui, o cenário urbano se apresenta como goticamente claustrofóbico, e também, ao mesmo tempo, dotado das mesmas qualidades de grandiosidade, majestade, solenidade e imponência das construções do passado. Pensamos que, assim como os castelos e os casarões sombrios, o cenário da grande metrópole ultrapassa o sujeito devido à sua incomensurabilidade e à sua inapreensibilidade. O sublime burkeano também se faz perceber em tal cenografia, pois a metrópole da era industrial e pós-industrial nos parece ser o palco mais dramático de todos os que têm teatralizado a condição de exílio e desamparo do sujeito na modernidade, jogado em um mundo labiríntico de simulacros e fantasmagorias. Aqui, também, no cenário da grande metrópole urbana, nos parece haver certa grandiosidade trágica tão cara ao Gótico, onde a História também exibe os seus detritos e suas ruínas.

Passando para os personagens, os sujeitos da História gótica, há um certo paradoxo em se usar o termo "vilão gótico". Etimologicamente, as palavras "vil", "vilão", "vilania" estão associadas à "vila", "burgo". Tais adjetivos difamatórios provavelmente surgiram nos castelos medievais como pecha aos habitantes das vilas, dos burgos - em suma, aqueles pertencentes à classe média, à burguesia - por parte dos nobres castelões. Em A feiticeira, o historiador francês do século XIX Jules Michelet nos mostra como tais castelões odiavam os burgueses das vilas 
florescentes e os ridicularizavam sempre que podiam (MICHELET, 1974, p. 50-53). "Com sua língua ao nobre o vil decepa", diz o terceiro verso do soneto "Neste mundo é mais rico o que mais rapa", do poeta barroco brasileiro Gregório de Matos (1633-1696), para quem, no soneto em questão, o mundo estaria em desconcerto pois a burguesia ataca a nobreza e rouba-lhe o poder. Para Gregório, tributário de uma visão de mundo marcada pelo apego à tradição em vias de desaparecer, o burguês é sempre o vilão. Tal embate entre burguesia e aristocracia culminou com a vitória da primeira em fins do século XVIII, como se sabe. O aristocrata passou a ocupar o lugar do "outro", passou a representar no imaginário da era democrática a alteridade radical, apresentado muitas vezes na ficção como o monstro. De Byron a Drácula, pelo menos, os vampiros são sempre aristocratas.

Tal alteridade radical da aristocracia no mundo moderno estabelece um liame estreito não apenas entre essa classe social e a História, mas também entre a mesma e a monstruosidade (BARROS, 1994, p. 29-36). Na literatura gótica essa relação se faz presente desde o Príncipe Manfredo, de Otranto. Mas, nos romances góticos setecentistas, quando a personagem vilanesca/monstruosa não pertence a uma alta linhagem, esta faz parte do alto clero católico, também ligado à alteridade e à vilania para o mundo protestante anglo-saxão.

Nem sempre, no entanto, esta vinculação da personagem gótica vilanesca/monstruosa com a aristocracia se dá de forma literal. No imaginário ocidental, a aristocracia está bastante associada ao dispêndio e à ociosidade. No século XIX, a estirpe dos dândis baudelairianos e decadentistas, em sua postura anti-burguesa, identificava-se como "aristocratas de espírito" em seu culto esteticista a tudo que fosse o avesso do ideal burguês e capitalista de trabalho e produtividade. Assim, o esteta refinado, com o seu dandismo, muitas vezes também irá encarnar o vilão/monstro gótico, como vemos nas obras de Joris-Karl Huysmans, Villiers de L’Isle Adam, Oscar Wilde e João do Rio, para citarmos alguns. Mesmo quando não são dândis, os monstros góticos urbanos, geralmente, não participam do esquema de trabalho e produtividade do capitalismo, sendo, portanto, considerados marginais, ociosos e perversos como os aristocratas. Aristocratas de espírito, como os dândis decadentistas, e também, como estes, fantasmas da História, em seu anacronismo face ao mundo moderno.

Cumpre ressaltar que nem toda transgressão, por si só, remete ao modo ou ao gênero gótico. Nem sempre a transgressão vem numa moldura gótica. Nem todo monstro é gótico, nem todo personagem que traz os traços da perversidade ou da psicopatia são góticos. Não há nada de gótico nos monstros de H. P. Lovecraft. Pois não há neles o selo que possa inscrevê-los na fantasmagoria da História. Também pensamos não haver nada de gótico na tela "American 
Gothic" (1930), do pintor norte-americano Grant Wood, pois o casal retratado - fazendeiros do Meio-Oeste estadunidense, absolutamente prosaicos - não apresentam tal selo da História ou nem mesmo os signos da transgressão, o que demonstra como o termo "gótico" tem sido muitas vezes usado em contextos que com ele não possuem nenhuma relação.

Para concluirmos, cumpre também assinalar que nem sempre as narrativas de terror ou de horror podem ser consideradas góticas. Nem toda narrativa fantástica é gótica. No Gótico, a partir do que expusemos aqui, seria necessário, portanto, haver a presença da cultura e da História, seria necessário o choque entre a tradição e o passado recalcados, de um lado, e a modernidade, de outro. O Gótico é intrínseco à modernidade e, pela junção de aristocracia com monstruosidade, apresenta uma nostalgia da aura. Pois o Gótico não é apenas sombrio, tétrico e assustador: ele precisa ter certa poeticidade na melancolia e na grandeza trágica de seus cenários majestosos, labirínticos e arruinados. Para Mario Praz, "a beleza amaldiçoada" da equação "majestade e ruína" é "um atributo permanente de Satã" (PRAZ, 1991, p. 58) e tal dimensão "diabólica" - talvez o halo sinistro do gênero e do modo góticos - tem se traduzido através dos séculos nas fantasmagorias da modernidade e na contínua vampirização da História.

\section{REFERÊNCIAS}

AGAMBEN, Giorgio. Estâncias: a palavra e o fantasma na cultura ocidental. Trad. Selvino José Assmann. Belo Horizonte: Ed. UFMG, 2007.

BARROS, Fernando Monteiro de. Aristocracia e monstruosidade: nostalgia da aura na Crônica da casa assassinada de Lúcio Cardoso. Dissertação (Mestrado em Letras Vernáculas). Faculdade de Letras, Universidade Federal do Rio de Janeiro. Rio de Janeiro, p. 129. 1994.

BARROS, Fernando Monteiro de. Do castelo à casa-grande: o "Gótico brasileiro" em Gilberto Freyre. Revista SOLETRAS, São Gonçalo, v.1, no 27, p. 80-94, jan.-jun. 2014. Encontrado em https://www.e-publicacoes.uerj.br/index.php/soletras/article/view/13050/10335 Acesso em 20.set.2020.

BAUDRILLARD, Jean. Simulacros e simulação. Trad. Maria João da Costa Pereira. Lisboa: Relógio d'Água, 1991.

BENJAMIN, Walter. Origem do drama barroco alemão. Trad. Sérgio Paulo Rouanet. São Paulo: Brasiliense, 1984.

BLOOM, Harold. O cânone ocidental: os livros e a escola do tempo. Trad. Marcos Santarrita. Rio de Janeiro: Objetiva, 1995. 
BOTTING, Fred. In Gothic Darkly: Heterotopia, History, Culture. In: PUNTER, David (editor). A new companion to the Gothic. Oxford: Wiley-Blackwell, 2012.

FRANÇA, Júlio. Introdução. In: (org.). Poéticas do mal: a literatura do medo no Brasil (1840-1920). Rio de Janeiro: Bonecker, 2017.

HOGLE, Jerrold E. The ghost of the counterfeit in the genesis of Gothic. In: SMITH, Allan Lloyd and SAGE, Victor (editors). Gothick Origins and Innovations. Amsterdam: Rodopi, 1994.

JUNKES, Lauro. "O processo de alegorização em Walter Benjamin”. Anuário de Literatura, Florianópolis, n.2, p.125-137, $1994 . \quad$ Encontrado em https://periodicos.ufsc.br/index.php/literatura/article/view/5361/4758 Acesso em 20.Jul.2020.

MATOS, Olgária Chaim Feres. Benjaminianas. Cultura capitalista e fetichismo contemporâneo. São Paulo: Ed. UNESP. 2010.

MATOS, Olgária C. F. Os arcanos do inteiramente outro: a Escola de Frankfurt, a melancolia e a revolução. 2.ed. São Paulo: Brasiliense, 1995.

MERQUIOR, José Guilherme. Os estilos históricos na literatura ocidental. In: PORTELLA, Eduardo (org.). Teoria literária. Rio de Janeiro: Tempo Brasileiro, 1979.

MICHELET, Jules. A feiticeira. Trad. Ronaldo Werneck. São Paulo: Círculo do Livro, 1974.

PAGLIA, Camille. Personas sexuais: arte e decadência de Nefertite a Emily Dickinson. Trad. Marcos Santarrita. São Paulo: Companhia das Letras, 1992.

PAZ, Octavio. Signos em rotação. Trad. Sebastião Uchôa Leite. 2.ed. São Paulo: Perspectiva, 1990.

PRAZ, Mario. The Romantic agony. Transl. Angus Davidson. Oxford: Oxford University Press, 1991.

PUNTER, David. Introduction: The Ghost of a History. In: (editor). A new companion to the Gothic. Oxford: Wiley-Blackwell, 2012.

ROSENFELD, Anatol. Shakespeare e o pensamento renascentista. In: Texto/contexto. 3.ed. São Paulo: Perspectiva, 1976.

Recebido em 30/9/2020.

Aceito em 09/12/2020. 